\title{
PENGGUNAAN ALGORITMA NEWTON - RAPHSON UNTUK MEMBUAT SOFTWARE PENENTUAN DOSIS OBAT
}

\author{
Ibnu Gunawan \\ Fakultas Teknologi Industri, Jurusan Teknik Informatika, Universitas Kristen Petra \\ Jl. Siwalankerto 121 - 131, Surabaya 60236, Indonesia \\ E-mail: ibnu@petra.ac.id
}

\begin{abstract}
ABSTRAK: Software USCPACK buatan University of Carolina merupakan salah satu pelopor dimungkinkannya penentuan dosis obat persatuan waktu tertentu untuk pasien secara umum menggunakan komputer. Software ini bekerja dengan menggunakan metode dasar Bayesian. Algoritma yang digunakan oleh software ini adalah NPEM (Non Parametric Expectation Maximization). Setelah mengetahui cara kerja dari USCPACK maka dibuatlah sebuah software pendosisan obat menggunakan algoritma non parametrik lain selain NPEM. Paper ini akan membahas pembuatan software pendosisan obat menggunakan algoritma newton - raphson dalam penentuan dosis obat terkomputerisasi.
\end{abstract}

Kata kunci: Pendosisan terkomputerisasi, optimasi, Bayesian, NPEM, Newton Raphson, USCPACK

\begin{abstract}
USCPACK Software from University of Carolina is one of the pioneers of computerized drug dosage system. This software uses Bayesian method. The algorithm that used in this software is known as NPEM (Non Parametric Expectation Maximization). After knowing how USCPACK work, then we made new software that has the same use like USCPACK but with new algorithm that different from NPEM. These paper will describe the how to make the software based on NPAG algorithm.
\end{abstract}

Keywords: Dosage computerized, optimation, Bayesian, NPEM, Newton Raphson, USCPACK

\section{PENDAHULUAN}

Pendosisan terkomputerisasi dilaksanakan dengan mensimulasikan jalannya obat di dalam tubuh pasien menggunakan farmakokinetik. Implementasi farmakokinetik secara komputasi numerik telah meningkatkan proses simulasi dalam komputer menjadi lebih cepat dan akurat.

Keterkaitan hubungan antara data dan kondisi pasien dengan penentuan dosis obat tidak mempunyai fungsi yang mudah didefinisikan. Oleh sebab itu pemodelan pendosisan obat ini harus dilakukan dengan metode non-parametrik. Perpaduan metode ini dengan data imputasi, yaitu Nonparametric Expectation and Maximization (NPEM), diunggulkan untuk dapat secara adaptif menaksir parameter populasi pendosisan obat ini. Paket program farmakokinetik, USCPACK buatan University of Carolina telah menggunakan algoritma NPEM untuk mengolah data pasien yang bersifat nonparametrik ini untuk menghasilkan suatu pola mixture yang nantinya akan digunakan sebagai distribusi prior dalam proses pendosisan individu secara Bayesian.

Algoritma NPEM ini mempunyai 2 fase yaitu pencarian likelihood dan maksimasi likelihood [1]. Pada fase maksimasi likelihood, NPEM menggunakan metode gaussian quadrature yang terbukti kurang efisien dibandingkan dengan metode maksimasi likelihood menggunakan NPAG (Non Parametric
Adaptive Grid) yang dipadukan dengan metode newton. Makalah ini akan membahas pembuatan software pendosisan otomatis dengan menggunakan platform matlab dan metode newton yang digunakan untuk menggantikan metode gaussian quadrature dalam NPEM. Sehingga pada akhirnya bisa lebih efisien dalam mendapatkan distribusi prior populasi yang sangat menentukan untuk pengambilan keputusan dosis obat bagi seorang pasien.

\section{METODE}

\section{Farmakokinetik}

Definisi Farmakokinetik menurut Shargel (2004) adalah ilmu yang mempelajari kinetika dari penyerapan obat, pendistribusian dan eliminasinya di dalam tubuh (misal melalui ekskresi dan metabolisme). Pembelajaran farmakokinetik melibatkan pendekatan eksperimental dan teoritikal.

Pendekatan teoritis dari pembelajaran farmakokinetik diantaranya adalah bagaimana mengembangkan model farkakokinetik yang bisa memperkirakan disposisi obat. Penerapan statistik merupakan bagian terintegrasi dari studi farmakokinetik. Metode statistik digunakan untuk mengestimasi parameter - parameter yang ada pada farmakokinetik dan interpretasi data guna mendesain dan memperkirakan dosis obat yang optimal untuk seseorang atau sekumpulan pasien. 
Farmakokinetik menggunakan model matematis untuk memodelkan proses penyerapan obat dalam tubuh manusia. Model matematis yang sederhana dan cukup dikenal dalam dunia farmakokinetik bernama compartment based model.

Gambar 1 menunjukkan single compartment model. Dalam single compartment model, diasumsikan bahwa obat diberikan secara IV (intravena-di injeksikan ke dalam tissue/jaringan tubuh penderita). Asumsi yang digunakan pada model kompartemen tunggal adalah tubuh penderita merupakan "open" body, dalam arti obat bisa masuk dan keluar dari tubuh dan tubuh penderita merupakan satu kesatuan yang memberi respon uniform. Satu kompartemen dianggap sebagai suatu jaringan atau sekelompok jaringan yang mempunyai aliran darah dan afinitas obat yang serupa. Setiap kompartemen dianggap sebagai sistem yang homogen sehingga obat dianggap berdistribusi secara merata. Semua proses laju obat masuk dan keluar dari kompartemen dinyatakan dengan tetapan laju $(k)$.

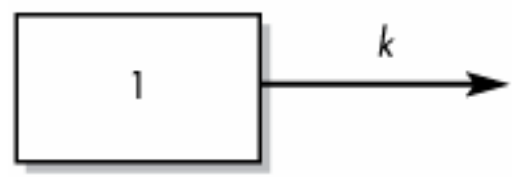

\section{Gambar 1. Single compartment model}

Pada model satu kompartemen, persamaan untuk meramalkan konsentrasi obat teramati (Y) untuk pada berbagai waktu (t) pengambilan sampel setelah pemberian obat dinyatakan dalam model struktural berikut [1]:

$\mathrm{Y}=\frac{\mathrm{D}}{\mathrm{V}} \exp \left(-\frac{\mathrm{Cl}}{\mathrm{V}} \mathrm{t}\right)+\varepsilon$

Dimana Y adalah konsentrasi obat dalam darah, D adalah dosis obat, $\mathrm{V}$ adalah volume distribusi, $\mathrm{Cl}$ adalah clearance obat, dan $t$ adalah waktu. Sedangkan $\varepsilon$ adalah error yang menyertai perhitungan statistika.

\section{Newton Raphson}

Metode Newton Raphson yang digunakan pada NPAG (Non Parametric Adaptive Grid) dinamai sebagai Primal-dual Interior-Point oleh penciptanya [2]. Metode ini bertujuan untuk mencari nilai maksimum sebuah fungsi melalui turunan pertama (jacobian) dan turunan keduanya (hessian). Berikut adalah rumus dasar dari Newton Raphson untuk sebuah fungsi $f(x)$ dan data $\mathrm{x}_{0}$ :

$x_{n+1}=x_{n}-\frac{f^{\prime}\left(x_{n}\right)}{f^{\prime \prime}\left(x_{n}\right)}$
Dimana $f^{\prime}\left(x_{n}\right)$ adalah turunan pertama fungsi $\mathrm{n}$ pada data $x_{n}$ dan $f^{\prime}\left(x_{n}\right)$ adalah turunan kedua fungsi n pada data $x_{n}$.

\section{Non Parametrik Adaptive Grid (NPAG)}

NPAG adalah pengembangan dari metode NPEM dimana fase II dari NPEM yang menggunakan Gaussian quadrature diganti menjadi Newton Raphson [3].

\section{HASIL DAN DISKUSI}

\section{Farmakokinetik}

Farmakokinetik mempunyai rumus dasar

$$
\mathrm{Y}=\frac{\mathrm{D}}{\mathrm{V}} \exp \left(-\frac{\mathrm{Cl}}{\mathrm{V}} \mathrm{t}\right)+\varepsilon
$$

Dimana Y adalah konsentrasi obat dalam darah, D adalah dosis obat, $\mathrm{V}$ adalah volume distribusi, $\mathrm{Cl}$ adalah clearance obat, dan $t$ adalah waktu. Sedangkan $\varepsilon$ adalah error yang menyertai perhitungan statistika. Dengan sebaran data berupa distribusi normal, sehingga mempunyai likelihood dengan persamaan:

$\mathrm{L}_{\mathrm{IJ}}=\prod_{\mathrm{k}=1}^{\mathrm{K}} \frac{1}{\sqrt{2 \pi \sigma_{\mathrm{k}}^{2}}} \mathrm{e}^{\left[-\frac{1}{2} \sum_{\mathrm{k}=1}^{\mathrm{K}}\left(\frac{\left(\mathrm{Y}_{\text {obs }}\left(\mathrm{t}_{\mathrm{k}}\right)-\mathrm{Y}_{\text {pred }}\left(\mathrm{t}_{\mathrm{k}}\right)\right.}{\sigma \mathrm{k}}\right)^{2}\right]}$

Dimana $Y_{\text {obs }}\left(t_{k}\right)$ adalah konsentrasi obat hasil pengamatan, $Y_{\text {pred }}\left(t_{k}\right)$ adalah konsentrasi obat hasil pemodelan statistika (persamaan (3)), dan $\sigma$ adalah error.

$\mathrm{Y}_{\text {pred }}\left(\mathrm{t}_{\mathrm{k}}\right)=\frac{\mathrm{D}}{\mathrm{V}} \exp \left(-\frac{\mathrm{Cl}}{\mathrm{V}} \mathrm{t}\right)+\varepsilon$

Dengan mensubstitusikan (5) ke dalam (4) maka ditemukanlah likelihood yang harus dimaksimasi menggunakan newton raphson

$\mathrm{L}_{\mathrm{IJ}}=\prod_{\mathrm{k}=1}^{\mathrm{K}} \frac{1}{\sqrt{2 \pi \sigma_{\mathrm{k}}^{2}}} \mathrm{e}^{\left[-\frac{1}{2} \sum_{\mathrm{k}=1}^{\mathrm{K}}\left(\frac{\left(\mathrm{Y}_{\text {obs }}\left(\mathrm{t}_{\mathrm{k}}\right)-\left(\frac{\mathrm{D}}{\mathrm{V}} \exp \left(-\frac{\mathrm{Cl}}{\mathrm{V}} \mathrm{t}\right)+\varepsilon\right)\right.}{\sigma \mathrm{k}}\right)^{2}\right]}$

Likelihood hasil substitusi (6) ini mempunyai variabel $\mathrm{V}, \mathrm{Cl}$ dan $\sigma$. sehingga akan mempunyai 3 turunan yaitu turunan $\mathrm{ke} \mathrm{V}$, turunan $\mathrm{ke} \mathrm{Cl}$ dan turunan $\mathrm{ke} \sigma$.

Berikut ini akan disajikan rumus lengkap newton raphson untuk $\mathrm{V}, \mathrm{Cl}$ dan $\sigma$. 


$$
\begin{aligned}
& \sigma_{n+1}=\sigma_{n}+\left[\begin{array}{l}
2 \sigma- \\
\left(\sigma^{-1} \sum\left(X_{i}-\left(\frac{\mathrm{D}}{\mathrm{V}} \exp \left(-\frac{\mathrm{Cl}}{\mathrm{V}} \mathrm{t}\right)+\varepsilon\right)\right)^{2}\right) \\
\left(3 \sigma^{-2} \sum\left(X_{i}-\left(\frac{\mathrm{D}}{\mathrm{V}} \exp \left(-\frac{\mathrm{Cl}}{\mathrm{V}} \mathrm{t}\right)+\varepsilon\right)\right)^{2}\right)
\end{array}\right] \\
& \mathrm{V}_{\mathrm{n}+1}=\mathrm{V}_{\mathrm{n}}+\left[\begin{array}{c}
{\left[\left(\frac{\mathrm{DCl}}{\mathrm{V}^{2}} \exp \left(-\frac{\mathrm{Cl}}{\mathrm{V}}(\mathrm{t})\right)\right)+\right]} \\
\left(\frac{\mathrm{X}_{\mathrm{i}}}{\sigma}\right)-\left(\frac{\mathrm{X}_{\mathrm{i}} \mathrm{Cl}}{\sigma \mathrm{V}}\right) \\
\left.-\left(\frac{\mathrm{D}}{\mathrm{V}} \exp \left(-\frac{\mathrm{Cl}}{\mathrm{V}}(\mathrm{t})\right)\right)\right] \\
{\left[\left(\exp \left(-\frac{\mathrm{Cl}}{\mathrm{V}}(\mathrm{t})\right)\right)\left(\frac{-3 \mathrm{D}}{\mathrm{V}^{2}}+\frac{2 \mathrm{D}}{\mathrm{V}^{3}} \mathrm{Cl}\right)\right]+} \\
{\left[\frac{2 \mathrm{X} \mathrm{i}_{\mathrm{i}}}{\sigma \mathrm{V}}+\left(\frac{\mathrm{X}_{\mathrm{i}} \mathrm{Cl}^{2}}{\sigma \mathrm{V}^{3}}\right)\right.}
\end{array}\right]+ \\
& C l_{n+1}=C l_{n}+\left[\frac{\left(\frac{D}{V} \exp \left(-\frac{C l}{V}(t)\right)\right)-\frac{X_{i}}{\sigma}}{\left(2 \frac{D}{V} \exp \left(-\frac{C l}{V}(t)\right)\right)+\frac{X_{i}}{\sigma V}}\right]
\end{aligned}
$$

$$
\begin{aligned}
& \left(\frac{\mathrm{XCl}^{2}}{\mathrm{~V}^{3}}\right)=\mathrm{K} \\
& \left(\frac{4 \mathrm{XCl}}{\mathrm{V}^{2}}\right)=\mathrm{L}
\end{aligned}
$$

Sedangkan untuk persamaan (9) maka bisa dipecah sebagai berikut:

$$
\begin{aligned}
& \frac{\mathrm{D}}{\mathrm{V} \sigma_{\mathrm{K}}^{2}} \exp \left(-\frac{\mathrm{Cl}}{\mathrm{V}} \mathrm{t}\right)=\mathrm{M} \\
& (X)=\mathrm{N}
\end{aligned}
$$

$$
\begin{aligned}
& \frac{2 \mathrm{D}}{\mathrm{V} \sigma_{\mathrm{K}}} \exp \left(-\frac{\mathrm{Cl}}{\mathrm{V}} \mathrm{t}\right)=\mathrm{O} \\
& \left(\frac{\mathrm{X}}{\mathrm{V}}\right)=\mathrm{P}
\end{aligned}
$$

Hal ini dilakukan agar tidak terjadi kesalahan perhitungan karena kompleksitas rumus sangat tinggi.

\section{Requirement, Spesifikasi, dan Asumsi}

\section{Implementasi pada matlab}

Berikut akan dibahas implementasi dari rumus (7) dan (8) pada matlab. Untuk mempermudah implementasi maka rumus (9) dipecah dalam beberapa bagian sebagai berikut untuk pembilang $\mathrm{Vn}$ :

$$
\begin{aligned}
& \frac{\mathrm{D} \mathrm{Cl}}{\mathrm{V}^{2} \sigma^{2}} \exp \left(-\frac{\mathrm{Cl}}{\mathrm{V}}(\mathrm{t})\right)=\mathrm{A} \\
& X=\mathrm{C} \\
& \left(\frac{\mathrm{XCl}}{\mathrm{V}}\right)=\mathrm{D} \\
& \left(\frac{\mathrm{D}}{\sigma_{K}^{2} \mathrm{~V}} \exp \left(-\frac{\mathrm{Cl}}{\mathrm{V}} \mathrm{t}\right)\right)=\mathrm{F}
\end{aligned}
$$

Sedangkan untuk penyebut Vn, rumus (8) dipecah menjadi sebagai berikut:

$$
\begin{aligned}
& \frac{-3 \mathrm{D}}{\mathrm{V}^{2} \sigma^{2}} \exp \left(-\frac{\mathrm{Cl}}{\mathrm{V}}(\mathrm{t})\right)=\mathrm{G} \\
& \frac{6 \mathrm{D} \mathrm{Cl}}{\mathrm{V}^{3} \sigma^{2}} \exp \left(-\frac{\mathrm{Cl}}{\mathrm{V}}(\mathrm{t})\right)=\mathrm{H} \\
& \frac{2 \mathrm{D} \mathrm{Cl} \mathrm{l}^{2}}{\mathrm{~V}^{4} \sigma^{2}} \exp \left(-\frac{\mathrm{Cl}}{\mathrm{V}}(\mathrm{t})\right)=\mathrm{I} \\
& \left(\frac{2 \mathrm{X}}{\mathrm{V}}\right)=\mathrm{J}
\end{aligned}
$$

\section{a. Requirement}

Membuat sebuah software yang bisa menghitung distribusi populasi menggunakan algoritma NPAG pada matlab

b. Spesifikasi

Software yang dibuat pada matlab dengan algoritma NPAG ini harus:

1. Sesuai dengan rumus yang telah diturunkan oleh NPAG

2. Bisa menerima inputan berupa data injeksi pasien dan dosis obat

3. Bisa memberikan output berupa parameter distribusi farmakokinetik seperti V, $\mathrm{Cl}$ dan sigma

4. Teruji kebenaran dari proses nya dengan cara membandingkan output dari software ini terhadap software lain yang menggunakan algoritma NPEM yang merupakan basis dari algoritma NPAG

c. Asumsi

Asumsi yang digunakan dalam pembuatan software ini adalah:

1. Dibuat di matlab.

2. Untuk rumus NPAG harus dibuat sendiri tidak boleh menggunakan newton raphson yang ada pada matlab.

3. 1 pasien mempunyai 2 data injeksi dan 1 dosis obat $\mathrm{mg} / \mathrm{kg}$ berat badan dan menggunakan data dari RSSA Malang pada tahun 1997. 
4. Untuk mempercepat proses maka dipakailah konstanta alfa sesuai dengan temuan Marquadt pada tahun 1963, bahwa harus ada konstanta kecil yang ditambahkan pada hessian sehingga hasilnya selalu semi definit positif [3].

\section{d. Desain}

Berdasarkan persamaan (7) dan (8) yang telah disederhanakan menjadi A-P dalam sub bab 2 maka diagram alir dari program matlab adalah seperti yang terdapat pada Gambar 2.

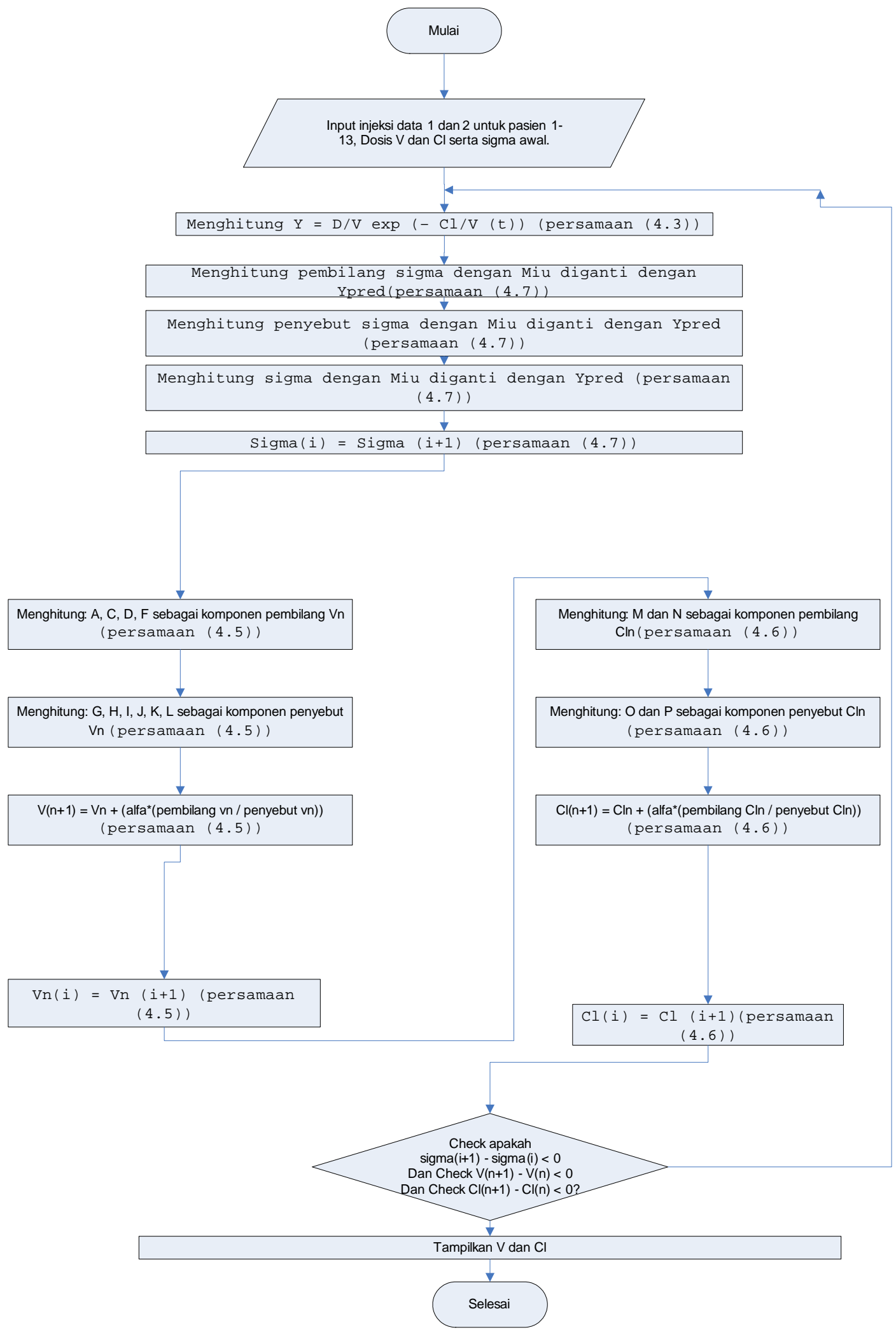

Gambar 2. Diagram Alir Program NPAG pada Matla 


\section{Uji Coba Program}

Pengujian efisiensi metode dilakukan dengan menggunakan data pasien gagal ginjal yang diambil dari RSSA Malang tahun 2007 seperti yang terlihat pada Tabel 1. Dari Tabel 1 dapat ditarik beberapa kesimpulan diantaranya:

1. Pasien 7 dan 8 mempunyai data injeksi yang sama yaitu sebesar $1.82 \mathrm{mg} / \mathrm{kg}$

2. Data dari tiap tiap pasien bersifat independent satu terhadap lainnya.

Data yang diambil dari tabel 1 diantaranya adalah:

1. Dosis / BB (D)

2. Rata rata konsentrasi cuplikan 1 dan $2\left(X_{1}\right.$ dan $\left.X_{2}\right)$ Untuk kemudian digabungkan dengan:

1. Standard deviasi $\sigma_{0}$ dari standar deviasi data $X_{1}$ dan $\mathrm{X}_{2}$ per pasien.

2. $\mathrm{V}_{0}=20$ melihat dari pengamatan-pengamatan sebelumnya

3. $\mathrm{K}_{\mathrm{el}}=0.2$ melihat dari pengamatan-pengamatan sebelumnya sehingga

4. $\mathrm{Cl}_{0}=4$

Tabel 1. Data 13 pasien dari RSSA Malang 1997

\begin{tabular}{|c|c|c|c|c|c|c|c|c|c|c|c|}
\hline \multirow{3}{*}{ No } & \multicolumn{3}{|c|}{ Dosis } & \multicolumn{8}{|c|}{ Waktu pengambilan Cuplikan* } \\
\hline & & \multirow{2}{*}{$\begin{array}{c}\text { Yang } \\
\text { Diberi- } \\
\text { kan } \\
\text { (mg) }\end{array}$} & \multirow{2}{*}{$\begin{array}{c}\text { Dosis/ } \\
\text { BB } \\
\mathrm{mg} / \mathrm{kg}\end{array}$} & \multicolumn{4}{|c|}{ Cuplikan I } & \multicolumn{4}{|c|}{ uplikan II } \\
\hline & & & & & & $\begin{array}{l}\text { trrasi } \\
\text { (ml) }\end{array}$ & $\begin{array}{l}\text { Rata- } \\
\text { rata } \\
\text { (ug/ml) }\end{array}$ & Jam & & trasi** & $\begin{array}{c}\text { Rata- } \\
\text { rata } \\
\text { (ug/ml) }\end{array}$ \\
\hline 1 & SUD & 80 & 1,19 & 5,00 & 1,70 & 1,72 & 1,710 & 7,75 & 0,9 & 0,92 & 920 \\
\hline 2 & HAR & 80 & 1,57 & 4,33 & 2,34 & 2,4 & 2,410 & 7,00 & 1, & 1, & 1,600 \\
\hline 3 & SOF & 80 & 1,60 & 5,75 & 2,71 & 2,73 & 2,720 & 7,75 & 2,34 & 2,35 & 2,345 \\
\hline 4 & SUM & 80 & 1,01 & 5,97 & 0,95 & 0,99 & 0,970 & 7,80 & 0,75 & 0,78 & 0,765 \\
\hline 5 & ISM & 80 & 1,48 & 4,75 & 2,2 & 2,2 & 2,265 & 7,83 & 1,4 & 1,38 & 1,39 \\
\hline 6 & AHM & 80 & 1,51 & 5,83 & 1,25 & 1,2 & 1,255 & 8,00 & 0,87 & 0,86 & 0,865 \\
\hline 7 & ROC & 80 & 1,82 & 4,00 & 1,82 & 1,81 & 1,815 & 6,92 & 0,92 & 0,91 & 0,915 \\
\hline 8 & DJU & 80 & 1,82 & 4,00 & 2,02 & 1,98 & 2,000 & 6,92 & 1,12 & 1,15 & 1,135 \\
\hline 9 & MUL & 80 & 1,43 & 4,17 & 2,04 & 1,9 & 1,995 & 7,00 & 1,29 & 1,20 & 1,245 \\
\hline 10 & URI & 80 & 1,86 & 4,58 & 1,30 & 1,2 & 1,270 & 7,17 & 0,88 & 0,91 & 0,895 \\
\hline 11 & SOE & 80 & 1,45 & 5,00 & 1,61 & 1,48 & 1,545 & 7,00 & 1,06 & 1,00 & 1,030 \\
\hline 12 & SUW & 80 & 1,60 & 4,83 & 3,38 & 3,33 & 3,355 & 7,00 & 3,14 & 3,09 & 3,115 \\
\hline 13 & $\mathrm{ADI}$ & 80 & 1,33 & 6,67 & 1,46 & 1,45 & 1,455 & 8,00 & 0,95 & 0,94 & 0,945 \\
\hline
\end{tabular}

Data yang ada di atas dimasukkan ke dalam perulangan untuk rumus newton raphson bagi ketiga variabel $\sigma, \mathrm{V}$, dan $\mathrm{Cl}$. Kemudian diiterasi sampai dengan:

1. $\sigma_{n+1}-\sigma_{n} \leq 0.1$

2. $\mathrm{V}_{\mathrm{n}+1}-\mathrm{V}_{\mathrm{n}} \leq 0.1$

3. $C l_{n+1}-C l_{n} \leq 0.1$

menggunakan matlab. Dari data pasien pertama, dengan 2 iterasi, bisa dihasilkan Tabel 2 .

Tabel 2 bisa dibandingkan dengan Tabel 3 yang merupakan hasil tetapan farmakokinetik dari algoritma NPEM. Tabel 3 dihasilkan oleh algoritma NPEM setelah melalui 175 iterasi [4]. Tabel 4 adalah hasil selisih untuk parameter V, Kel dan CL dari Tabel 3 dan Tabel 4.
Tabel 2. Hasil tetapan farmakokinetik dari NPAG

\begin{tabular}{crrr}
\hline Grid & \multicolumn{1}{c}{ V } & \multicolumn{1}{c}{ K } & CL \\
\hline 1 & 23.01447754 & 0.174806118 & 4.023071471 \\
2 & 6.005481583 & 0.334049819 & 2.006130033 \\
3 & 17.01291559 & 0.236036489 & 4.015668864 \\
4 & 18.0197697 & 0.167188827 & 3.012704166 \\
5 & 19.01010374 & 0.05360526 & 1.019041546 \\
6 & 20.01326753 & 0.150860929 & 3.019220137 \\
7 & 16.00943066 & 0.125930601 & 2.01607722 \\
8 & 18.01127753 & 0.167564107 & 3.018043637 \\
9 & 33.02020001 & 0.122115854 & 4.032289921 \\
10 & 20.01035995 & 0.025984569 & 0.519960572 \\
11 & 37.02230944 & 0.108981293 & 4.034739161 \\
12 & 15.01050851 & 0.200835336 & 3.014640524 \\
\hline Rata-rata & 20.18000848 & 0.155663266 & 2.810965604 \\
\hline
\end{tabular}

Tabel 3. Hasil tetapan farmakokinetik dari NPEM

\begin{tabular}{crrr}
\hline Grid & \multicolumn{3}{c}{ NPEM } \\
\cline { 2 - 4 } (pasien ke) & \multicolumn{1}{c}{$\mathbf{V}$} & Kel & \multicolumn{1}{c}{ CL } \\
\hline 1 & 23.4003907000 & 0.172143558 & 4.028226514 \\
2 & 6.6601562500 & 0.317626953 & 2.115445136 \\
3 & 17.4267578000 & 0.233361816 & 4.066739847 \\
4 & 18.9296875000 & 0.202148438 & 3.82660676 \\
5 & 19.4238261000 & 0.072534179 & 1.408891279 \\
6 & 20.1601562000 & 0.165673828 & 3.340010251 \\
7 & 16.9296875000 & 0.155566408 & 2.633690673 \\
8 & 18.3789063000 & 0.194970703 & 3.583348282 \\
9 & 33.7011719000 & 0.136645508 & 4.605113754 \\
10 & 20.0078125000 & 0.036035156 & 0.720984645 \\
11 & 37.2617188000 & 0.133056641 & 4.957919141 \\
12 & 15.4296875000 & 0.222753907 & 3.437023174 \\
\hline Rata-rata & 20.6424965875 & 0.1702097579 & 3.226999954 \\
\hline
\end{tabular}

Tabel 4. Selisih hasil dari algoritma NPAG dan NPEM

\begin{tabular}{cccc}
\hline Grid & delta V & delta K & delta Cl \\
\hline 1 & 0.385913162527 & -0.002662559779 & 0.005155042648 \\
2 & 0.654674667210 & -0.016422865518 & 0.109315103346 \\
3 & 0.413842212417 & -0.002674673055 & 0.051070983316 \\
4 & 0.909917798855 & 0.034959610592 & 0.813902593458 \\
5 & 0.413722364208 & 0.018928919408 & 0.389849733575 \\
6 & 0.146888667018 & 0.014812898784 & 0.320790114048 \\
7 & 0.920256841303 & 0.029635807260 & 0.617613452585 \\
8 & 0.367628770634 & 0.027406595877 & 0.565304644330 \\
9 & 0.680971889902 & 0.014529654085 & 0.572823833805 \\
10 & -0.002547451149 & 0.010050587360 & 0.201024072993 \\
11 & 0.239409358476 & 0.024075347766 & 0.923179979977 \\
12 & 0.419178985546 & 0.021918570803 & 0.422382650420 \\
\hline Rata-rata & 0.462488105579 & 0.014546491132 & 0.416034350375 \\
\hline & & &
\end{tabular}

\section{KESIMPULAN}

Penggantian metode gauss jordan dengan newton raphson dapat meningkatkan kecepatan penghitungan numeris algoritma NPEM secara cukup signifikan.

Namun yang disayangkan bahwa penggantian ini di sisi lain menyebabkan penurunan rumus menjadi lebih komplek karena tiap variabel harus diturunkan satu persatu. 


\section{DAFTAR PUSTAKA}

1. Leary, R., 2001, An Adaptive Grid Non Parametric Approach to Pharmacokinetic and Dynamic (PK/PD) Population Models, Proceedings of the Fourteenth IEEE Symposium on Computer-Based Medical Systems

2. Leary, H. R., 2007, An Evolutionary Non Parametric NLME Algorithm, PAGE Meeting, France.
3. Bonate, P.L., 2006, Pharmacokinetic-Pharmacodynamic Modeling and Simulation, Springer.

4. Prastyo, D., 2008, Pemodelan Farmakokinetika Populasi dan Individu Menggunakan Algoritma EM-Nonparametrik dan Analysis Bayesian, ITS.

5. Suprapti, B., 1997, Farmakokinetika Populasi dari Gentamisin: Studi pada Penderita Bedah Urologi, Tesis Magister, Universitas Airlangga, Surabaya. 